\title{
Políticas de transferência de renda: componentes utópicos e realização na América Latina
}

\section{POLÍTICAS DE TRANSFERÊNCIA DE RENDA: COMPONENTES UTÓPICOS E}

REALIZAÇÃO NA AMÉRICA LATINA

Políticas de transferencia de rentas: componentes utópicos y realizaciones en América Latina.

Politiques de transferts sur le revenu : éléments utopiques et réalisations dans l'Amérique Latine

Basic income policies: utopian components and achievement in Latin America

\section{Eveline Algebaile, Denise Rissato e Roberto Arruda}

\section{CpenEdition}

Journals

\section{Edição electrónica}

URL: http://journals.openedition.org/espacoeconomia/2621

DOI: 10.4000/espacoeconomia.2621

ISSN: 2317-7837

\section{Editora}

Núcleo de Pesquisa Espaço \& Economia

\section{Refêrencia eletrónica}

Eveline Algebaile, Denise Rissato e Roberto Arruda, « Políticas de transferência de renda:

componentes utópicos e realização na América Latina », Espaço e Economia [Online], 10 | 2017, posto online no dia 14 julho 2017, consultado o 30 abril 2019. URL : http://journals.openedition.org/ espacoeconomia/2621 ; DOI : 10.4000/espacoeconomia.2621

Este documento foi criado de forma automática no dia 30 Abril 2019.

(C) NUPEE 


\title{
Políticas de transferência de renda: componentes utópicos e realização na América Latina
}

\author{
POLÍTICAS DE TRANSFERÊNCIA DE RENDA: COMPONENTES UTÓPICOS E \\ REALIZAÇÃO NA AMÉRICA LATINA \\ Políticas de transferencia de rentas: componentes utópicos y realizaciones en \\ América Latina. \\ Politiques de transferts sur le revenu : éléments utopiques et réalisations dans \\ l'Amérique Latine
}

Basic income policies: utopian components and achievement in Latin America

Eveline Algebaile, Denise Rissato e Roberto Arruda

1 Entre fins do século XIX e meados do século XX, em diversos países, especialmente na Europa e Norte da América, foram constituídos modernos sistemas de proteção social relacionados às situações hegemonicamente identificadas como de risco para a vida coletiva, como o desemprego, a fome, a doença, a invalidez e a velhice. Os sistemas concretizados nesse contexto e seus componentes utópicos constituem uma conquista das democracias modernas, por assegurarem formas de estabilidade socioeconômica frente às instabilidades da vida social ou por delinearem horizontes de possibilidades capazes de mover lutas e ações orientadas para transformações políticas.

2 Com a crise e as consequentes alterações no modelo de acumulação capitalista ocorridas a partir na década de 1970, mesmo os países que haviam alcançado altos padrões de organização econômico-social, constituindo sólidos sistemas de proteção vinculados ao trabalho, passam a se confrontar com a ampliação e o agravamento de problemas sociais relacionados às condições de inserção econômica de variados segmentos populacionais.

Como mostram, dentre outros autores, Robert Castel e Fernando Álvarez-Uría ${ }^{1}$, vários dos elementos estruturantes da promessa integradora do Estado de Bem Estar Social então consolidada, com destaque para o pleno emprego e a universalização de políticas sociais, 
passam a apresentar crescentes limitações, resultando no aumento do número de pessoas cuja relação com o trabalho passa a se dar segundo padrões que não asseguram condições estáveis de provisão de necessidades básicas e de planejamento do futuro.

4 Em regiões periféricas, a crise apresenta especificidades relevantes em relação aos problemas sociais e aos modos de sua problematização. No caso da América Latina, como mostram Florestan Fernandes e Francisco de Oliveira $^{2}$, a formação econômico-social dos países da região já havia legado um estoque de desigualdades econômicas e sociais de difícil superação devido a sua gravidade, extensão e profundo enraizamento na própria organização do território, incidindo incisivamente na constituição tanto das forças sociais e políticas quanto da estrutura e das práticas político-institucionais que regem os processos por meio dos quais os problemas da vida coletiva são reconhecidos e enfrentados como problemas da vida pública3 ${ }^{3}$.

5 Nesses países, portanto, como mostram os estudos de Aldaíza Spozati e Lena Lavinas ${ }^{4}$, o estoque de problemas a enfrentar no contexto da crise relaciona-se não apenas a situações econômico-sociais instauradas no presente, mas também, e de forma bastante destacada, à forma como estas se fundem com as desigualdades estruturais historicamente consolidadas, incluindo suas ramificações nas formas de organização do Estado e de utilização do fundo público e da estrutura estatal, regidas por culturas políticas que tendem à reprodução ampliada do que Florestan Fernandes ${ }^{5}$ chamou de "excedente de poder". Por meio desse termo, o autor acentua o fato de que as desigualdades, na periferia do capitalismo, não assentam primordialmente na repartição desigual do excedente econômico, mas nas fusões entre poder econômico e poder político que, além de renovarem formas de apropriação patrimonialista do Estado, reiteram as distâncias sociais que impedem a disputa menos assimétrica das políticas econômica e social.

6 Contudo, ainda que nesse contexto as propostas de ajuste do Estado às necessidades do capital se mostrem hegemônicas, surgem, como lembra Horácio $\mathrm{Capel}^{6}$, diversas proposições de enfrentamento dos problemas sociais portadoras de referências utópicas importantes para a compreensão do presente e das possibilidades de futuro.

7 A compreensão da afirmação acima apresentada requer uma explicitação da noção de utopia com a qual trabalhamos neste artigo. Sem ignorar a variedade de sentidos atribuídos ao termo, entendemos primariamente as utopias como sistemas de ideias que conjugam, obrigatoriamente, a crítica à realidade presente com proposições de realidades alternativas. Cabe lembrar que, como alerta Eagleton ${ }^{7}$, há formulações utópicas constituídas em perspectivas políticas variadas, inclusive claramente opostas. Tanto as críticas como as alternativas propostas podem portar visões fantasiosas que projetam sociedades idílicas, sem compromisso com quaisquer referências às condições concretas de produção da vida coletiva. Ou podem expressar compreensões conservadoras que consagram o passado ou o presente, reiterando suas regras e hierarquias e as elevando à condição de normas que devem ser aplicadas implacavelmente sobre o futuro, de modo a colonizá-lo. Para Eagleton, "o melhor tipo de pensamento utópico" deve rejeitar "ambos os casos", mantendo "presente e futuro em tensão, apontando para as forças ativas no presente que podem levar além dele".

8 A problematização de Eaglethon permite ponderar que, em uma utopia compromissada com as condições coletivas de sua realização no curso da história, o cenário futuro traçado não deve ser entendido como uma realidade a ser produzida sem mediações. Sua potência, neste caso, não está na sua capacidade de se realizar plenamente, mas nas 
tensões que é capaz de colocar em movimento no presente. A lembrança de Eduardo Galeano $^{8}$ a respeito da definição de utopia feita pelo diretor de cinema argentino Fernando Birri, expressa com clareza e com rara beleza essa perspectiva: "ella [a utopia] está en el horizonte. Me acerco dos pasos, ella se aleja dos pasos. Camino diez pasos y el horizonte se corre diez pasos más allá. Por mucho que yo camine, nunca la alcanzaré. Para que sirve la utopia? Para eso sirve: para caminhar."

Essas considerações nos permitem retornar com maior propriedade à discussão das propostas de enfrentamento dos problemas sociais que surgem no contexto da crise dos anos 1970, lembrando que um exemplo expressivo, neste caso, são as inúmeras proposições de políticas de transferência de renda orientadas para cobrir as lacunas de inserção econômica e social então constituídas, políticas estas elaboradas como tentativa de resposta aos desafios de organização da vida coletiva evidenciados no referido contexto.

10 Um marco a destacar, neste âmbito, é a criação da Basic Income European Network (Rede Europeia da Renda Básica) - BIEN, que assume, em 2004, a forma de uma rede mundial, a partir de então denominada Basic Income Earth Network, nome que possibilita tanto a manutenção da sigla original, BIEN, como a ampliação de seu sentido.

11 Constituída no início da década de 1980 como uma organização destinada a difundir concepções, políticas e práticas de concessão de uma renda básica a todo cidadão com o objetivo de se lhes garantir condições mínimas de subsistência independentemente das suas condições de acesso ao trabalho ${ }^{9}$, a BIEN pode ser entendida como um movimento cuja expansão tem influído na disseminação de políticas de transferência de renda no continente europeu e em outras regiões do mundo. Sua ideia de renda básica tem componentes utópicos relevantes, expressos tanto na crítica à realidade presente, quanto na proposta de realidade apresentada como horizonte a ser construído e alcançado, e quanto, ainda, nas formas como as referências utópicas são convertidas em ferramenta política, já que a realidade proposta é sistematicamente vinculada a programas de ação orientados para a disseminação das práticas entendidas como necessárias à sua construção.

12 As formas concretas predominantemente assumidas pelas políticas de renda efetivamente implantadas nesse contexto, no entanto, têm diferenças importantes em relação às proposições originais de renda básica que constituem o ideário e os programas de ação da BIEN.

13 Tendo por base pesquisas sobre o surgimento e a expansão de programas de transferência de renda condicionada (PTRC) no contexto latino americano ${ }^{10}$, este artigo se dirige à análise dessas proposições e de sua disseminação, considerando sua ramificação na América Latina e o quadro dos PTRC constituídos nos países da região a partir de então, correlacionando suas características com o ideário disseminado pela proposta da BIEN e discutindo os impasses, limitações, potencialidades e desafios evidenciados a partir dessa correlação.

\section{Aspectos da criação, organização e proposições da BIEN}

14 Como dito anteriormente, a BIEN foi formada no início da década de 1980 como um movimento vinculado a um projeto de desenvolvimento e difusão de ideias e ações relacionadas à concessão de uma renda básica incondicional para todos os cidadãos. Tal movimento, no entanto, adquiriu rapidamente a forma de uma organização estruturada, 
cuja consolidação e ramificação têm se dado, desde o início, por meio de diversas vias ${ }^{11}$, destacando-se, para os fins deste trabalho, a realização de congressos bianuais em diferentes países e a constituição de redes nacionais ou regionais associadas.

Os congressos da BIEN foram originalmente realizados na Europa, em conformidade com as próprias delimitações iniciais da referida rede ao continente europeu. $01^{\circ}$ congresso da BIEN ocorreu em 1986, na Bélgica, na Universidade Católica de Louvain, Louvain-laNeuva, no período de 4 a 6 de setembro daquele ano. Nos dezesseis anos seguintes, os congressos bianuais ocorreram novamente na Bélgica (1988) e, na sequência, na França (1990), Itália (1992), Reino Unido (1994), Áustria (1996), Países Baixos (1998), Alemanha (2000), Suíça (2002) e Espanha (2004).

Em 2004, oficializa-se a ampliação da rede para escala mundial, modificando-se seu nome e parte de seu programa de ações. Assim, dezoito anos após o $1^{\circ}$ congresso, sua realização sai pela primeira vez do continente europeu, cabendo à África do Sul sediar o $11^{\circ}$ congresso, de 2 a 4 de novembro de 2006, na Universidade de Cape Town, Cidade do Cabo. No mesmo ano (2006) foi fundada a rede da África do Sul afiliada à BIEN, denominada "Studies in Poverty and Inequality Institute (SPII)".

A filiação do Brasil à BIEN ocorreu em 2004 com a fundação da "Rede Brasileira de Renda Básica de Cidadania". Foi nesse país, 6 anos depois, de 30 de junho a 02 de julho de 2010, que ocorreu o primeiro congresso da BIEN realizado na América do Sul, sediado na Universidade de São Paulo (USP).

O deslocamento do congresso da BIEN para o continente asiático ocorre apenas em 2016, com a realização do $16^{\circ}$ congresso em Seul, Coreia do Sul, no período de 7 a 9 de julho, com a temática "Transformação Social Ecológica e a Renda Básica".

No que diz respeito às redes associadas, em 2016 a BIEN reconhecia 29 redes nacionais de renda básica e duas redes regionais, presentes nos continentes Europeu, Africano, Americano, Asiático e Oceania, conforme apresentado no Quadro 1.

Quadro 1 
Redes nacionais e regionais associadas à Basic Income Earth Network (BIEN)

\begin{tabular}{|c|c|c|}
\hline Ano de constituição & Pais/Região & Rede \\
\hline 1984 & Reino Unido & $\begin{array}{l}\text { Citizen's Income Trust } \\
\text { (Confiança de Renda do Cidadão, inicialmente denominada Income } \\
\text { Research Group Basic) }\end{array}$ \\
\hline 1991 & Paises Baixos & \begin{tabular}{|l} 
Vereniging Basisinkomen - VBI \\
(Associação Renda Básica )
\end{tabular} \\
\hline 1995 & Irlanda & \begin{tabular}{|l} 
Basic Income Ireland \\
(Rede Renda Básica Irlanda)
\end{tabular} \\
\hline 1999 & Estados Unidos da América & $\begin{array}{l}\text { U.S. Basic Income Guarantee Network -USBIG } \\
\text { (Rede de Garantia de Renda Básica dos Estados Unidos) }\end{array}$ \\
\hline 2000 & Dinamarca & $\begin{array}{l}\text { BIEN Denmark (Borgerlonsbevægelsen) } \\
\text { (BIEN Dinamarca) }\end{array}$ \\
\hline 2001 & Espanha & $\begin{array}{l}\text { Red Renta Basica } \\
\text { (Rede Renda Básica) }\end{array}$ \\
\hline$\overline{2002}$ & Áustria & $\begin{array}{l}\text { Netzwerk Grundeinkommen und sozialer Zusammenhalt - } \\
\text { B.I.E.N. Austria } \\
\text { (Rede Renda Básica e Coesão Social) }\end{array}$ \\
\hline 2002 & Austrália & $\begin{array}{l}\text { Basic Income Guarantee Australia (BIGA) } \\
\text { (Renda Básica de Garantia Austrália) }\end{array}$ \\
\hline 2002 & Suiça & $\begin{array}{l}\text { BIEN Switzerland } \\
\text { (BIEN Suiça) }\end{array}$ \\
\hline 2004 & Brasil & Rede Brasileira de Renda Básica de Cidadania \\
\hline 2004 & Argentina & $\begin{array}{l}\text { Red Argentina de Ingreso Ciudadano } \\
\text { (Rede Argentina de Ingresso Cidadão) }\end{array}$ \\
\hline 2004 & Alemanha & $\begin{array}{l}\text { Netzwerk Grundeinkommen } \\
\text { (Rede Renda Básica) }\end{array}$ \\
\hline$\overline{2006}$ & África do Sul & $\begin{array}{l}\text { Studies in Poverty and Inequality Institute -SPII } \\
\text { (Instituto de Estudos da Pobreza e da Desigualdade) }\end{array}$ \\
\hline 2007 & Japão & $\begin{array}{l}\text { BIEN Japan } \\
\text { (BIEN Japão) }\end{array}$ \\
\hline 2008 & Canadá & $\begin{array}{l}\text { Basic Income Canada Network / Réseau canadien pour le } \\
\text { revenu garanti } \\
\text { (Rede de Renda Básica do CanadáRede Canadense para o rendimento } \\
\text { garantido) }\end{array}$ \\
\hline
\end{tabular}

\begin{tabular}{|c|c|c|}
\hline 2008 & México & $\begin{array}{l}\text { Red Mexicana Ingreso Ciudadano Universal } \\
\text { (Rede Mexicana de Ingresso Cidadão Universal) }\end{array}$ \\
\hline \multirow[t]{2}{*}{2008} & & Bin Italia - Basic Income Network Italy \\
\hline & Itália & (Rede de Renda Básica da Itália) \\
\hline \multirow[t]{2}{*}{2009} & & Basic Income Korean Network (BIKN) \\
\hline & Coréia do Sul & (Rede Coreana de Renda Básica) \\
\hline \multirow[t]{2}{*}{2010} & & Sekcija za promocijo UTD v Sloveniji \\
\hline & Eslovênia & (Seção de Promoção da Renda Básica Universal da Eslovênia) \\
\hline \multirow[t]{2}{*}{2011} & & BIEN Finland - Suomen perustuloverkosto \\
\hline & Finlândia & (BIEN Finlândia-Rede de Renda Básica da Finlândia) \\
\hline 2012 & Bélgica & $\begin{array}{l}\text { Belgian Network for Basic Income } \\
\text { (Rede Belga para Renda Básica) }\end{array}$ \\
\hline \multirow[t]{2}{*}{2012} & & Borgerlonn BIEN Norge \\
\hline & Noruega & (Salário Cidadão BIEN Noruega) \\
\hline$\overline{2013}$ & Portugal & Rendimento Básico \\
\hline 2013 & França & $\begin{array}{l}\text { Mouvement Français Pour un Revenu de Base } \\
\text { Movimento Francês Para uma Renda Básica) }\end{array}$ \\
\hline 2014 & Europa & $\begin{array}{l}\text { Unconditional Basic Income Europe - UBI-Europe } \\
\text { (Renda Básica Incondicional Europa ) }\end{array}$ \\
\hline$\overline{2016}$ & Canadá & $\begin{array}{l}\text { Revenue de Base Québec - RBQ } \\
\text { (Renda Básica Quebec) }\end{array}$ \\
\hline 2016 & China & BIEN China \\
\hline 2016 & Índia & $\begin{array}{l}\text { India Network for Basic Income - INBI } \\
\text { (Rede Indiana para Renda Básica) }\end{array}$ \\
\hline 2016 & Nova Zelândia & $\begin{array}{l}\text { Basic Income New Zealand Incorporated - BINZ } \\
\text { (Renda Básica Incorporada da Nova Zelândia) }\end{array}$ \\
\hline 2016 & Escócia & $\begin{array}{l}\text { Citizen's Basic Income Network Scotland - SCIO } \\
\text { (Rede de Renda Básica do Cidadão da Escócia) }\end{array}$ \\
\hline$\overline{2016}$ & Taiwan & $\begin{array}{l}\text { Network Taiwan } \\
\text { (Rede Taiwan) }\end{array}$ \\
\hline
\end{tabular}

Fonte: BIEN. Disponível em: http://www.basicincome.org/about-bien/affiliates/ (Os nomes das redes foram traduzidos livremente pelos autores)

Nas proposições dessas redes, podem ser observados alguns pontos convergentes importantes. Elas têm como base comum a proposta de distribuição de uma renda básica, 
universal, incondicional e individual, potencialmente suficiente para prover as necessidades básicas de cada indivíduo. A defesa da renda básica universal encontra fundamento na constatação das desigualdades de condições de acesso e produção da vida material. A distribuição equitativa de uma renda básica objetiva minimizar os efeitos da base social desigual e atenuar os efeitos da pobreza, presentes nos diferentes continentes e modos de vida.

Quanto à relação da renda básica com o trabalho, parte-se em geral do pressuposto de que, garantido o acesso a uma renda básica incondicional, o indivíduo teria liberdade para escolher qual tipo de trabalho executaria, considerando-se que já disporia, por meio da renda básica, de um lastro para suprir as necessidades básicas. Assim, dos pontos de vista teórico e prático, liberdade e necessidade, quando combinadas, atuariam como reguladoras das relações no campo do trabalho. Dito de outro modo, as pessoas disporiam de certas condições que lhes permitiriam escolher, com certo grau de liberdade, atividades laborais que gostariam de desempenhar. Por sua vez, por conta dessa liberdade, as atividades com menor propensão de execução, em cada contexto, devido a sua penosidade, insalubridade ou desprestígio, dentre outras desvantagens, seriam provavelmente melhor remunerados pelos empregadores e contariam com melhores condições de realização, minimizando-se os efeitos do trabalho precarizado e as baixas taxas de remuneração.

Como indicado anteriormente, pode-se reconhecer componentes utópicos importantes nesse núcleo de princípios e orientações que constituem a ideia de renda básica da BIEN. E a dimensão utópica parece estar presente não apenas no fato da proposta de renda básica se configurar como uma proposta de realidade apresentada como horizonte a ser construído e alcançado, mas também na sua clara vinculação a um programa de ação orientado para a disseminação tanto do ideário da renda básica quanto das práticas entendidas como necessárias a essa construção. O horizonte utopicamente delineado, neste caso, converte-se em ferramenta de ação política no presente. Isto fica evidente, por exemplo, no fato de que diversos aspectos estruturantes da realidade futura esperada, como a universalidade incondicional de uma renda básica, não são apenas "pontos de chegada", mas elementos a serem operados desde o presente como ferramentas capazes de tensionar as concepções, políticas e práticas vigentes, colocando-as em crise, e de construir gradualmente bases objetivas e subjetivas necessárias à implantação plena (ou seja, à consecução da universalidade) da renda básica.

De outro lado, cabe observar que tais componentes utópicos não se vinculam a pretensões igualitárias, mas a um projeto ético-político de redução de desigualdades que seria mais adequadamente situado no campo social democrático. A proposta da BIEN busca, neste sentido, atualizar valores de integração social constituídos em bases democráticas que só se sustentam se forem repactuados os mínimos toleráveis no novo quadro de vida coletiva em constituição ${ }^{12}$. Passemos a uma apreciação mais detida de seus elementos centrais.

A proposta da BIEN consiste na defesa da concessão universal - e, portanto, a todo cidadão - de uma renda básica desvinculada do trabalho, da renda real e de qualquer condicionalidade. Universalidade, incondicionalidade, individualidade/pessoalidade e uniformidade devem ser considerados, neste caso, os elementos centrais que definem e estruturam a proposta nos seus traços fundamentais.

25 A universalidade é o primeiro elemento de contraposição direta a qualquer tipo de discriminação, seletividade e discricionariedade. Pela perspectiva da universalidade, a 
referência de uma política de renda básica, no que diz respeito à cobertura, seria a população em toda a sua extensão, sem diferenciações relativas a renda, posses ou quaisquer outros elementos constitutivos das condições de vida.

o princípio da incondicionalidade reforça isto, já que, ao impedir a instituição de condições para o recebimento da renda, também impede o estabelecimento de dinâmicas de controle que impliquem restrições e suspensões temporárias ou definitivas em decorrência de eventuais descumprimentos de condicionalidades. O alcance desse princípio, porém, é mais amplo que o reforço da universalidade. Por vincular-se também ao objetivo de não restringir, por quaisquer meios ou critérios, a elegibilidade de qualquer pessoa à concessão da renda, implica decisiva contraposição a mecanismos de controle social, reforçando uma compreensão da renda básica como direito inalienável, cuja garantia não implica a sobreposição de valores morais, normas e códigos de conduta de alguns grupos sobre outros, e não gera por si hierarquias de autoridade, sentimentos de dependências e práticas de vigilância e suspeição.

o princípio da individualidade ou pessoalidade busca afirmar o indivíduo como unidade padrão que referencia as ações da política de renda básica. Não se trata, neste caso, da afirmação do individualismo como valor, mas da individualidade como medida e critério de uma renda destinada ao bem-estar que deve independer das redes de pertencimento de cada indivíduo.

o princípio da uniformidade, por fim, assenta-se na ideia de que, na medida em que todas as pessoas são elegíveis, todas devem receber de forma equitativa. Reforça, neste sentido, os argumentos vinculados aos demais princípios, já que a universalidade, a incondicionalidade e a individualidade pressupõem não discricionariedade e, portanto, oposição a que a caracterização de cada indivíduo interfira na implementação da renda. Segundo o princípio da uniformidade, se a concessão independe das características individuais e familiares, tais características também não podem balizar diferenciações na própria renda concedida.

Nas formulações e debates da BIEN, esses quatro princípios também aparecem correlacionados à operacionalização da renda básica, já que sua aplicação rigorosa restringe a montagem de aparatos burocráticos vinculados ao cadastramento, caracterização e controle dos beneficiários, assim como ao cálculo da diferenciação das rendas concedidas.

Deve-se observar, contudo, que o debate desses princípios e orientações gerais não se mantém apartado dos contextos de realização de políticas de algum modo relacionadas às proposições da BIEN. A análise dos congressos da Rede, neste caso, evidencia que, no decorrer da sua constituição e ampliação, suas proposições fundamentais foram sendo gradualmente correlacionadas tanto aos problemas enfrentados pelos Estados nacionais em face das alterações econômicas e políticas vinculadas à reestruturação da acumulação capitalista, quanto aos projetos e experiências que passam a emergir, nesse contexto, como tentativa de resposta aos novos quadros econômico-sociais.

31 A sequência de temas dos congressos expressa essa crescente correlação. Observa-se, inicialmente, a reiteração das questões centrais da Rede na constituição dos temas: como o aprofundamento da própria ideia de renda básica e da discussão das condições de bem estar coletivo, de combate à pobreza, ao desemprego e à fome, e dos tipos de desestruturação dos mecanismos de proteção social. Gradualmente, porém, vão sendo incorporados temas relacionados a questões macroestruturais, como as relativas à 
reestruturação econômica e aos impasses entre modelos produtivos e a questão ecológica observada desde o ponto de vista das condições sociais de vida. No congresso realizado em 2016, na Coreia do Sul, o tema apresenta exatamente a questão da conservação/ restauração ecológica na interface com a questão da renda básica, evidenciando a intenção da Rede em reconhecer o debate sobre as mudanças estruturais nas formas de produção da vida material como fundamento necessário para o debate teórico e prático sobre a renda básica.

Porém, a análise dos processos de implantação de políticas de transferência de renda e dos variados perfis a elas atribuídos em diferentes contextos evidencia que existem distanciamentos e contradições importantes entre as formas concretas assumidas por essas políticas e a proposição de renda básica da BIEN.

\section{Renda básica e renda mínima na composição e disseminação das políticas de transferência de renda na América Latina}

Todo o movimento e a organização gerados pela BIEN nas suas três décadas de existência têm influenciado, por diferentes vias, a constituição de propostas de políticas de transferência de renda em diversos países e regiões. Não raramente, porém, as propostas concretas de políticas de renda implantadas na maior parte dos países se diferenciam significativamente da ideia de renda básica e de seus quatro princípios fundamentais. Nas políticas concretas, prevalece um modelo de renda mínima, não universal, vinculada a condicionalidades, definida e diversificada em função de características individuais, familiares e, mesmo, territoriais.

Num quadro comparativo entre a renda básica e a renda mínima, as questões relativas à incondicionalidade e à relação com o trabalho parecem constituir o núcleo central de diferenciação. É muito presente nas proposições e nas políticas de renda mínima a ênfase na identificação de características que possibilitem agrupar indivíduos segundo condições específicas de necessidades sociais que sirvam de base ao estabelecimento de diferentes categorias de programas (ou de concessões e exigências diferenciadas dentro de um mesmo programa). É também bastante presente a ideia de transitoriedade da concessão da renda em função do objetivo de "autonomização" do indivíduo (em relação à renda concedida), autonomização esta correntemente vinculada ao trabalho. Ou seja, correntemente, a política de renda mínima é concebida como um mecanismo transitório que deve ser complementado por estratégias que auxiliem os indivíduos a ingressarem ou reingressarem em relações de trabalho em tese capazes de lhes garantir as condições básicas de sobrevivência e de assim lhes propiciar a "autonomização" em relação à concessão de renda.

Observe-se, neste caso, que essa concepção está vinculada a modelos de programas de renda focalizados e definidos segundo marcadas diferenciações, em sentidos exatamente opostos aos princípios de universalidade e uniformidade que constituem a proposta da BIEN.

36 A disseminação dos programas de transferência de renda na Europa e em outros continentes tem implicado o predomínio dessa segunda perspectiva, denotando que a ideia de políticas de renda vem sendo apropriada hegemonicamente em um formato redutor quando comparado ao formato preconizado pelo movimento a favor da renda básica. Esse formato redutor dos programas de transferência de renda suscita críticas em 
relação a sua utilização como política de ajuste que acaba, muitas vezes, por favorecer o gradual desmonte do Estado social referenciado na constituição de serviços correlacionados a direitos universais.

37 Não faltam, porém, estudos, como os de Robert Castel ${ }^{13}$, que, ao assinalarem as contradições presentes nas políticas reais, também dão visibilidade a potencialidades que podem municiar lutas e disputas no campo dos direitos sociais e das políticas e eles referidas.

O levantamento das políticas de transferência de renda instituídas em diferentes regiões do mundo a partir dos anos 1980, bem como a análise dos seus processos de implantação e dos variados perfis a elas atribuídos, acessíveis por meio de pesquisa documental, especialmente no repositório de estudos da BIEN, ou em estudos acadêmicos como o de Zimmerman e Silva ${ }^{14}$, não deixam dúvidas quanto ao distanciamento entre a realidade e a proposta de renda básica da BIEN. E, como mostram estudos como os de Cecchini e Madariaga ${ }^{15}$ e Silva ${ }^{16}$, a análise dos programas de transferência de renda condicionadas (PTRC) na América Latina no mesmo período evidencia aspectos especialmente expressivos desse distanciamento, já que seus escopos e padrões de cobertura populacional tendem a limitá-los à contenção de situações muito agudas de destituição econômico-social.

39 Na América Latina, o debate sobre renda básica e sobre renda mínima já se mostra presente desde os anos iniciais da década de 1980. Mas é no final dessa década que começam a ser criados os primeiros programas instituídos em nível nacional.

o Quadro 2 apresenta, segundo uma ordem cronológica, os principais programas nacionais de transferência condicionada de renda ${ }^{17}$ criados a partir de então.

Quadro 2 
Programas de transferência condicionada de renda implantados em países da América Latina, segundo o ano de implantação

\begin{tabular}{|c|c|c|}
\hline $\begin{array}{c}\text { Ano } \\
\text { de } \\
\text { criaçăo }\end{array}$ & Pais & Nome do Programa \\
\hline \multirow[t]{2}{*}{1989} & México & Programa Nacional de Solidaridad (PRONASOL) \\
\hline & Venezuela & Programa Beca Alimentaria \\
\hline 1990 & Honduras & Programa de Asignación Familiar - PRAF \\
\hline 1996 & Brasil & Programa de Erradicação do Trabalho Infantil-PETI \\
\hline 1997 & México & Programa de Educación, Salud y Alimentación (PROGRESA) \\
\hline \multirow[t]{2}{*}{1998} & Equador & Programa Bono Soli dário \\
\hline & Honduras & Programa de Asignación Familiar II - PRAF BDD II \\
\hline 2000 & $\begin{array}{l}\text { Nicarágua } \\
\text { Costa Rica }\end{array}$ & $\begin{array}{l}\text { Red de Protección Social - RPS } \\
\text { Programa Superémonos }\end{array}$ \\
\hline \multirow{4}{*}{2001} & Brasil & Programa Bolsa-Escola \\
\hline & Brasil & Programa Bolsa Alimentação \\
\hline & Colómbia & Programa Familias em Acción \\
\hline & México & Programa Oportunidades \\
\hline \multirow[t]{2}{*}{2002} & Argentina & Programa Jefes y Jefas de Hogar Desocupados \\
\hline & $\begin{array}{l}\text { Chile } \\
\text { Brasil }\end{array}$ & $\begin{array}{l}\text { Programa Chile Solidário } \\
\text { Programa Bolsa Familia }\end{array}$ \\
\hline 2003 & Equador & Programa Bono de Desarrollo Humano \\
\hline \multirow{9}{*}{2005} & Argentina & Programa Ciudadania Porteña \\
\hline & $\begin{array}{l}\text { Argentina } \\
\text { Colômbia }\end{array}$ & \begin{tabular}{|l} 
Programa Familias por la Inclusión Social \\
Subsidios condicionados à Assistência Escolar
\end{tabular} \\
\hline & $\begin{array}{l}\text { E1 Salvador } \\
\text { Honduras }\end{array}$ & $\begin{array}{l}\text { Subsidios condicionados a Assistencla Escolar } \\
\text { Red Solicarias - Programa Comunidades Solidarias Rurales } \\
\text { Programa de Asignación Familiar III - PRAF BID III }\end{array}$ \\
\hline & Nicarágua & Sistema de Atención a Crisis - SAC \\
\hline & Paraguai & Progra \\
\hline & $\begin{array}{l}\text { Paraguai } \\
\text { Paraguai }\end{array}$ & $\begin{array}{l}\text { Programa Abrazo } \\
\text { Programa Nopytyvô }\end{array}$ \\
\hline & Peru & $\begin{array}{l}\text { Red Juntos (Programa Nacional de Apoyo Directo a los más } \\
\text { pobres) }\end{array}$ \\
\hline & $\begin{array}{l}\text { República } \\
\text { Dominicana }\end{array}$ & Programa Solidaridad \\
\hline & Uruguai & Plan de Atención Nacional a la Emergencia Social - PANES \\
\hline \multirow[b]{2}{*}{2006} & Bolivia & Programa Bono Juancito Pinto \\
\hline & Costa Rica & Programa Avancemos \\
\hline \multirow[b]{2}{*}{2007} & Colồmbia & 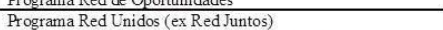 \\
\hline & Guatemala & $\begin{array}{l}\text { Programa de Protección y Desarrollo de la Niñez y } \\
\text { Adolescencia Trabajadora }\end{array}$ \\
\hline \multirow[b]{2}{*}{2008} & Guatemala & Programa Mi Familia Progresa - MIFAPRO \\
\hline & Uruguai & $\begin{array}{l}\text { Programa Nuevo Régimen de Asignaciones Familiares } \\
\text { (AFAM-PE) }\end{array}$ \\
\hline \multirow{2}{*}{2009} & Argentina & $\begin{array}{l}\text { Programa Asignación Univer sal por Hijo para a Protección } \\
\text { Social (AUHPS) }\end{array}$ \\
\hline & 71 & Programa Bono Madre, Niño-Niña "Juana Azurduy de Padilla \\
\hline
\end{tabular}

Fonte: Elaborado a partir de informações constantes em CEPAL, 2016 e Rissato (2015) ${ }^{18}$.

41 A análise dos perfis desses programas, bem como do conjunto por eles constituído, possibilita perceber aspectos relevantes de seus distanciamentos e contradições em relação à proposta de renda básica universal.

Primeiramente, cabe destacar que os escopos e os padrões de cobertura populacional de tais programas evidenciam a tendência predominante de sua utilização para a contenção das situações mais agudas de destituição econômico-social. Nesse caso, a definição desses escopos e delimitações de cobertura populacional, em geral, envolve a definição de linhas de pobreza e/ou miséria muito baixas.

De modo geral, tais programas estão voltados a segmentos populacionais e famílias pobres e extremamente pobres, implicando o estabelecimento de linhas de corte e critérios de elegibilidade extremamente restritivos.

No que diz respeito aos critérios de elegibilidade, a maioria dos programas pesquisados prioriza crianças e adolescentes menores de 18 anos, pessoas com deficiência, idosos, gestantes ou lactantes.

A centralidade da família como unidade beneficiária não se confirma como generalidade. A renda e/ou condição familiar aparecem com frequência como referência de destaque para a análise da elegibilidade dos beneficiários, mas não são por si o critério determinante da elegibilidade. Apenas em alguns casos (como Brasil, Chile, Colômbia, México, Nicarágua, Panamá e Paraguai) a família extremamente pobre recebe algum benefício quando não tem em sua composição pessoas nas condições acima identificadas. Pode haver variações nessas definições também em função de focalizações territoriais. Na 
Argentina, por exemplo, somente famílias extremamente pobres que vivem em Buenos Aires têm direito a um benefício fixo.

De modo geral, os programas analisados parecem desconsiderar ou tratar como aspecto bastante secundário a presença do homem na família. Raramente foram identificadas, nos programas pesquisados, atividades voltadas ao homem adulto (seja no âmbito da educação, da saúde ou da assistência). Essa ideia é reforçada pela centralidade conferida à mulher-mãe enquanto titular do benefício e foco de atividades nos âmbitos da saúde e da assistência. Ainda que a nucleação dos programas nas mulheres seja objeto de inúmeras avaliações positivas, em face do fenômeno contemporâneo da feminização da pobreza e, por conseguinte, do caráter mais regular de sua presença na vida familiar, dentre outros aspectos destacados, esse relativo apagamento do homem adulto como beneficiário das ações vinculadas aos programas parece naturalizar e mesmo reforçar a ausência do homem em atividades relacionadas aos cuidados e ao acompanhamento dos filhos, ensejando problematizações.

Os debates iniciais sobre a instituição de políticas de transferência de renda, em alguns países da região, como notadamente o Brasil ${ }^{19}$, destacavam o desemprego como situação nuclear para essa transferência. Nessa perspectiva, o homem adulto aparecia, inevitavelmente, como uma das categorias beneficiárias da renda e de programas complementares orientados para a inserção social e laboral.

cherísticas das administrações públicas nos países da região acabaram levando à adoção de programas centrados nas famílias e em condicionalidades vinculadas aos setores de educação e saúde. Nos países em que esses setores eram os mais estruturados, educação e saúde se tornaram os núcleos de operacionalização dos programas. Com o passar do tempo, observa-se, porém, uma expansão do setor de assistência social que, entre outros aspectos, tem implicado a criação de programas voltados à reinserção laboral que cobrem os segmentos masculinos adultos.

É interessante notar, contudo, que esta retomada não se dá no caso dos programas de transferência condicionada de renda de largo espectro, o que significa a não constituição de uma importante porta de entrada de homens pobres e com baixa expectativa de vida em um conjunto de práticas institucionais relacionadas ao trabalho e à saúde.

Uma outra observação necessária diz respeito à tendência a que os programas e ações relacionados à transferência de renda sejam significativamente diferenciados em um número significativo de país. Ou seja, nos estudos realizados, nota-se que a maioria dos países adotou diferentes programas e ações para atender a diferentes segmentos de beneficiários: crianças, adolescentes, mulheres, deficientes e idosos, como, por exemplo, na Argentina, na Colômbia, em El Salvador, no Paraguai, na Guatemala e no Equador. Em sentido diverso, Brasil, Chile, Nicarágua e México destacam-se por adotarem um único e abrangente Programa Nacional, voltado para todos os públicos, ainda que com diferenciações internas e sem detrimento da instituição de programas mais delimitados que acabam cobrindo parcialmente e de forma complementar as novas lacunas de inserção social que vão sendo reconhecidas.

51 Por fim, como já comentado, os programas de transferência de renda implementados na América Latina, de modo geral, têm condicionalidades vinculadas à educação e à saúde. A vinculação à educação exige, correntemente, matrícula e controle de frequência. A vinculação à saúde pode implicar uma variedade de acompanhamentos ou controles, como acompanhamento nutricional e de práticas preventivas como de vacinação. $\mathrm{Na}$ 
evolução de vários programas ao longo do tempo, no entanto, nota-se uma gradual ampliação da assistência social como setor responsável ou corresponsável pela coordenação e/ou execução do programa. É corrente, atualmente, a assistência social pagar o benefício e desenvolver atividades de controle, qualificação e reinserção no mercado de trabalho das populações beneficiárias.

\section{Considerações finais: limites e potencialidades na relação entre as práticas de renda mínima e a proposta de renda básica}

52 O acompanhamento do processo ao longo do qual foram constituídas as proposições de renda básica e as políticas de renda mínima permite perceber que a ideia de renda básica contribuiu para impulsionar a formulação, implementação e expansão de políticas de transferência de renda que, no entanto, tiveram seu perfil especialmente definido pelo ajuste estrutural do Estado realizado no contexto de crise de acumulação do capital. Observa-se, neste caso, que os elementos centrais da proposta de renda básica universalidade, incondicionalidade, individualidade/pessoalidade e uniformidade - além de se vincularem à problematização do presente e a proposições de uma realidade futura alternativa (aspectos típicos das formulações utópicas), são convertidos em fundamento de ações políticas que, porém, têm seus sentidos contraditoriamente modificados no curso de sua realização, envolvendo perdas em relação aos sentidos das proposições originais, mas também contraditórias e inusitadas conquistas.

O estudo dos programas de transferência de renda condicionada na América Latina dá visibilidade a várias dessas contradições cuja compreensão pode favorecer não apenas as lutas pela superação de limites, mas também mobilizações a favor de potencialidades às vezes pouco percebidas e exploradas.

Observa-se, por exemplo, grande assimetria entre os países no que diz respeito à cobertura, ao valor dos benefícios, ao caráter assumido pelas condicionalidades e à consolidação ou expansão dos programas ao longo do tempo. Alguns países avançaram mais do que outros, na medida em que abandonaram políticas isoladas e adotaram programas mais abrangentes, ampliando a população beneficiária, incluindo idosos, deficientes, jovens e a própria família de baixa renda, independentemente de que tenham em sua composição crianças e adolescentes. Isso pode ser entendido como avanço em direção aos princípios que estruturam a proposta da BIEN, já que uma política mais regular, com maior cobertura, mais unificada em sua operacionalização e menos diferenciada internamente tende a ser mais claramente identificada pelos beneficiários reais e potenciais, propiciando tanto uma procura mais regular quanto condições melhores de acompanhamento público.

Mas é igualmente interessante observar que, apesar dos inúmeros casos em que os programas se mostram incipientes, o conjunto de programas e sua disseminação são, por si, um dado expressivo. Tal disseminação está implicada com uma ampliação significativa do debate na região, o que pode significar avanços em termos do aprofundamento das especificidades latino-americanas, da maior organicidade dos países da região e do estabelecimento de agendas, pautas e espaços comuns de debate e formulação.

Outro aspecto a destacar diz respeito ao fato de que a implantação e a expansão dos programas em diversos países geraram inúmeras tensões relativas à incipiência de bases institucionais próprias (e mais apropriadas) para sua realização. A incipiência da 
estrutura institucional de setores de ação estatal, como o da assistência social, fez com que os setores de educação e saúde fossem escolhidos inicialmente, em alguns países, como operadores de alguns programas. Isto acabou gerando sobrecargas financeiras, materiais e funcionais para esses setores, mas também acabou pautando de forma mais intensa, no debate interno de cada um desses setores e no debate entre setores, os desafios relativos ao enfrentamento da pobreza em países nos quais as situações de destituição, além de não se circunscreverem aos aspectos econômicos imediatos, mais diretamente relacionados à inserção laboral, estão profundamente implicadas com o não acesso ou acesso precário a políticas públicas referidas aos mais fundamentais direitos humanos e sociais.

As ampliações dos programas (especialmente no sentido da ampliação de seus escopos e de seus padrões de cobertura populacional e territorial) implicaram, por conseguinte, alterações nas bases institucionais responsáveis por sua realização, envolvendo modificações nos setores inicialmente responsáveis, mas também novos padrões de constituição de setores antes pouco estruturados. É exemplar o caso da assistência social no Brasil que, nos anos 2000, com a definição, no âmbito da Política Nacional de Assistência Social (PNAS), de um Sistema Único de Assistência Social (SUAS), passa a ter a realização de programas sociais amparada na estruturação de Centros de Referência da Assistência Social (CRAS), entendidos como equipamentos públicos de base distrital a serem instalados e organizados em todo o território nacional, como parte das responsabilidades compartilhadas entre os três entes federativos - União, Estados e Municípios.

As novas estruturas em constituição crescem fermentadas por interessantes contradições. De um lado, é evidente o reiterado descompasso entre o volume e variedade de atividades anunciadas pelos governos e as bases reais disponíveis para sua realização, sendo frequentes as avaliações que apontam insuficiência e inadequação de espaços, materiais, equipamentos, recursos financeiros e equipes profissionais. De outro lado, comparando-se as novas bases funcionais com as anteriores, é igualmente evidente o seu crescimento, sendo forçoso reconhecer que, ao longo desse processo, tanto os problemas sociais inicialmente pautados, quanto outros ainda não incorporados pelas políticas governamentais, passaram a ter nova visibilidade, peso e reconhecimento no debate público sobre a questão social.

Essas contradições, por sua vez, dão lastro a novas formas de problematização da questão das condicionalidades. Vimos que, no debate clássico sobre renda básica, a incondicionalidade é defendida tanto por favorecer a universalização de uma política, quando por restringir práticas de controle, vigilância, suspeição e diferenciação que reiterariam ou ampliariam as hierarquias sociais. A realização concreta de programas de transferência condicionada de renda na América Latina, no entanto, mostra que as condicionalidades têm sido operadas, em diversos casos, mais como um recurso para aproximar sujeitos de instituições às quais não tinham acesso, e para familiarizá-los com práticas institucionais que deveriam compor o rol de suas legítimas reivindicações. Nessa perspectiva, ainda que a condicionalidade mantenha aspectos capazes de favorecer a vigilância e o controle, também funciona como um mecanismo impulsionador da assunção de responsabilidades por parte do Estado, pressionando a expansão da própria estrutura estatal necessária à operacionalização da política social e ampliando a busca e o acesso dos sujeitos às ações a ela vinculadas. 
60 Nesse contexto, notam-se três novos aspectos que, devidamente encarados como conquista social, podem vir a gerar novos frutos nas lutas por políticas públicas referidas a direitos: o crescimento exponencial do número de profissionais atuantes no campo ampliado da política social; o aprofundamento, maior qualificação e maior presença do debate crítico na formação desses profissionais; e sua maior mobilização em torno de questões, práticas e ações que extrapolam em muito os limites dos interesses corporativos de cada setor, orientando-se para a construção de formas de relação intersetorial e de produção de acúmulos coletivos vinculados às lutas por direitos sociais e de políticas públicas que garantam seu exercício. Essa nova força social tem, no nosso entender, características que favorecem sua organização como força política ${ }^{20}$ capaz de disputar os sentidos dos programas instituídos e de vincular essa disputa a projetos utópicos que coloquem a questão dos direitos humanos e sociais no centro do debate e da ação pública.

61 Assim, malgrado suas limitações, esses programas demonstram potencialidades relevantes em termos do debate, das lutas e das conquistas concretas em relação à questão das desigualdades sociais. Seja pela sua forma de presença no debate público, dando visibilidade aos quadros de pobreza, às assimetrias econômico-sociais, aos descompassos entre promessas políticas e formas reais de disputa e apropriação do fundo público, dentre outros aspectos polêmicos. Seja pelas novas bases institucionais, cuja constituição é inevitavelmente provocada pelas necessidades de sua operacionalização. Seja pelo novo quadro de inter-relações entre políticas setoriais que vai sendo constituído em face das novas condições de visibilidade e debate das situações complexas de destituição. Seja, por fim, pela intensificação da presença do debate crítico na formação inicial e continuada de profissionais do campo das políticas sociais.

\section{BIBLIOGRAFIA}

ALGEBAILE, Eveline. Políticas de escolarização e intersetorialidade: modelos e práticas de interrelação entre políticas sociais e política educacional em curso no Brasil [Relatório parcial de pesquisa]. Rio de Janeiro, PPFH/UERJ, mimeo, 2015. 45 p.

ARRUDA. Roberto. Emergência de um novo padrão de coesão social? Da proteção social ofertada pelo Programa Bolsa Família à inserção laboral. [Relatório parcial de Pesquisa]. Rio de Janeiro: PPFH/UERJ, mimeo, 2015. $30 \mathrm{p}$.

ÁLVAREZ-URÍA, Fernando. Retórica neoliberal. In: ALVAREZ-URÍA, F., G. SANTESMASES, A., MUGUERZA, J. PASTOR, J. RENDUELES, G. VARELA, J. (Comp.). Neoliberalismo versus democracia. Madrid: La piqueta, 1998, p. 353-384.

CAPEL, Horacio. Ciencia ciudadana, ética y política para viejos y nuevos problemas. Biblio 3W. Revista Bibliográfica de Geografía y Ciencias Sociales. [En línea]. Barcelona: Universidad de Barcelona, 30 de octubre de 2014, Vol. XIX, no 1096 <http://www.ub.es/geocrit/b3w-1096.htm> [22 de outubro de 2015] ISSN 1138-9796.

CASTEL, Robert. As metamorfoses da questão social: uma crônica do salário. Petrópolis: Vozes, 1998, $611 \mathrm{p}$. 
CASTEL, Robert. A discriminação negativa - Cidadãos ou autóctones? Petrópolis: Vozes, 2008, 136 p.

CECCHINI, Simone; MADARIAGA, Aldo. Programas de Transferencias Condicionadas: balance de la experiência reciente em América Latina y el Caribe. Cuadernos de la CEPAL, no 95 . Santiago de Chile. 2011. 220p.

CEPAL. Base de datos de programas de protección social no contributiva. Santiago de Chile: División de Desarrollo Social, CEPAL, 2016. < http://www.cepal.org/es/areas-de-trabajo/ desarrollo-social> [03 de março de 2016]

CEPAL. Estadísticas sociales. In: Anuário Estadístico de América Latina y el Caribe. Santiago de Chile: CEPAL, 2006a, p. 21. 276

CEPAL. La protección social de cara al futuro: acceso, financiamiento y solidaridad (LC/G.2294 (ses.31/3)). Montevideo, Uruguay: CEPAL, 2006b, 193 p.

CEPAL. Anuário Estadístico de América Latina y el Caribe. Santiago de Chile: CEPAL, 2012a.

CEPAL. Panorama Social de América Latina - 2011. Santiago de Chile: CEPAL, fev. 2012b.

CEPAL. Panorama Social da América Latina - 2012. Santiago de Chile: CEPAL, 2013.

EAGLETON, Terry. Utopias, past and present: why Thomas More remains astonishingly radical. The Guardian [On line]. United Kingdom, 16 october 2015, last modified on 23 october 2015. < http://www.theguardian.com/books/2015/oct/16/utopias-past-present-thomas-more-terryeagleton> [12 de fevereiro de 2016].

FERNANDES, Florestan. Mudanças sociais no Brasil. São Paulo: Difel, 1974, 359 p.

FERNANDES, Florestan. Capitalismo dependente e classes sociais na América Latina. Rio de Janeiro: Zahar Editores, 1975, 154 p.

GALEANO, Eduardo. Las palabras andantes. España: Siglo XXI, 1993, 328 p.

GRAMSCI, Antonio. Cadernos do cárcere. Volume 3. Maquiavel. Notas sobre o Estado e a política. Rio de Janeiro: Civilização Brasileira, 2000, 428 p.

LAVINAS, Lena. (coord.) et alli. Medindo o grau de aversão à desigualdade da população brasileira. [Relatório Técnico Final]. Brasília: FINEP, mimeo, 2012. 195 p.

MAGRO, Ana Fátima do Nascimento. A nova roupagem do controle e manutenção da pobreza: os Programas de Transferência Condicionada de Renda na América Latina. Tese Doutoral orientada pelo Prof. Dr. Carlos Nelson dos Reis. Porto Alegre: Pontifícia Universidade Católica do Rio Grande do Sul, 2012. $228 \mathrm{p}$.

OLIVEIRA, Francisco. A economia brasileira. Crítica à razão dualista. Estudos Cebrap, v. 2. São Paulo: Cebrap, 1972, p. 3-82.

OLIVEIRA, Francisco. Os direitos do antivalor: a economia política da hegemonia imperfeita. Petrópolis: Vozes, 1998, 231 p.

RISSATO, Denise. Políticas sociais, pobreza e risco infanto-juvenil no contexto de realização do Programa Bolsa Família em Foz do Iguaçu - Paraná. Tese Doutoral orientada por Eveline Algebaile. Rio de Janeiro: Universidade do Estado do Rio de Janeiro, 2015. 293 p.

SILVEIRA, Antônio Maria da. "Redistribuição da renda". Revista Brasileira de Economia, Rio de Janeiro, v. 29, n. 2, abr./jun. 1975, p. 3-15.

SILVA, Maria Ozanira da Silva e. Programas de transferência de renda na América Latina e Caribe. São Paulo: Cortez, 2015, 248 p. 
SPOSATI, Aldaíza (ed.). Renda mínima e crise mundial. Saída ou agravamento? São Paulo: Cortez, 1997, $123 \mathrm{p}$.

SUPLICY, Eduardo Matarazzo. Programas de garantia de renda mínima: um instrumento eficiente de combate à fome e à desigualdade. Revista Cultura Vozes, Petrópolis, RJ, v. 96. № 2, 2002, p.

5-14.

TELLES, Vera da Silva. Pobreza e cidadania. São Paulo: Editora 34, 2001, 167 p.

VAN PARIJS, Philippe. Renda básica: renda mínima garantida para o século XXI? Estudos Avançados, v. 14, n. 40, 2000, p. 179-210.

WANDERLEY, Luiz Eduardo. A questão social no contexto da globalização: o caso latino-Os enigmas do social. In: BELFIORE-WANDERLEY, M., BÓGUS, L., YASBEK, M.C. (orgs.). Desigualdade e a questão social. São Paulo: EDUCA, 2000, p. 51 - 151.

ZIMMERMANN, Clóvis; SILVA, Marina da Cruz. As experiências internacionais de renda mínima na redução da pobreza. Revista Espaço Acadêmico, 82, Março de 2008.

Disponível em: < http://www.espacoacademico.com.br/082/82zimmermann.htm > [ 02 de Janeiro de 2015] ISSN: 1519-6186.

\section{NOTAS}

1. Castel, 1998 e 2008, e Álvarez-Uría, 1998.

2. Fernandes, 1974 e 1975, e Oliveira, 1972 e 1998.

3. Telles, 2001.

4. Spozati,1997, e Lavinas, 2012.

5. Fernandes, 1974.

6. Capel, 2014.

7. Eagleton, 2015 (os trechos transcritos foram traduzidos livremente pelos autores).

8. Galeano, 1993, p. 310.

9. Van Parijs, 2000.

10. Algebaile, 2015, Rissato, 2015 e Arruda, 2015. Metodologicamente, as pesquisas se reportam a fontes bibliográficas e documentais relacionadas tanto às proposições de políticas de renda por parte de organizações de diversas linhagens e de diversas escalas, quanto às políticas efetivamente instituídas em diferentes países a partir dos anos 1980. No caso dos países latinoamericanos, para além da identificação dos programas instituídos, buscam-se dados e informações que possibilitem definir em seus traços fundamentais o perfil dos diferentes programas, bem como identificar aspectos do seu processo de implementação que interfiram no delineamento de seu perfil, cobertura e desdobramentos. Uma fonte fundamental, neste caso, são os anuários de estatísticas sociais da Comissão Econômica para a América Latina e o Caribe (CEPAL, 2006a, 2006b, 2012a, 2012b, 2013). As condições de realização das políticas são ainda investigadas por meio da análise de relatórios institucionais, relatórios de auditoria e estudos acadêmicos. Por fim, a experiência brasileira é também investigada por meio de pesquisa de campo junto a instituições públicas em diferentes regiões do país.

11. A principal forma de constituição da Rede se dá por meio da inscrição individual de membros, mediante uma contribuição financeira definida, em 2016, em um mínimo de 100 euros. Constituem atualmente a rede acadêmicos e ativistas dos mais variados países, destacando-se nomes como o sociólogo alemão Claus off, a economista brasileira Lena Lavinas e o filósofo austríaco André Gorz. 
12. A respeito das políticas sociais como instrumento de repactuação da vida coletiva em diferentes contextos, reportamo-nos, entre outros, a Castel, 1998 e 2008, e Van Parijs, 2000.

13. Castel, 1998 e 2008.

14. Zimmerman e Silva, 2008.

15. Cecchini e Madariaga, 2011.

16. Silva, 2015.

17. Nos países pesquisados, há variados programas de transferência não condicionada de renda que ampliariam e diversificariam em muito a correlação entre renda básica e renda mínima. Como, porém, na região, os programas de transferência condicionada são os que obtêm maior destaque, apresentando um desenvolvimento bastante implicado com alterações na estrutura estatal relacionada à política social, optamos por circunscrever a discussão a essa categoria de programas, considerando as contribuições ao debate que disso pode derivar.

18. O Quadro 2 é uma versão sintética de um quadro bem mais extenso, com a caracterização dos programas, elaborado por Rissato (2015) em sua Tese Doutoral e ampliado pela autora no âmbito da pesquisa por ela realizada em vinculação com este trabalho.

19. Conforme, por exemplo, ainda na década de 1970, a discussão feita por Silveira (1975) e, em seguida, por Eduardo Suplicy, em debates, pronunciamentos e matérias posteriormente sistematizados em textos como Suplicy (2002).

20. Para a distinção entre força social e força política, reportamo-nos à discussão clássica feita nas "Breves notas sobre a política de Maquiavel", por Antonio Gramsci (2000). Dessa discussão, é possível depreender, sinteticamente, que, para o autor, o termo "forças sociais" designa os variados agrupamentos sociais relacionados às diversas posições dos sujeitos no processo de produção de sua existência, enquanto o termo "forças políticas" designa os sujeitos coletivos constituídos pelas associações intencionais de sujeitos de um mesmo grupo ou de grupos afins em torno de interesses, questões, lutas e projetos comuns, ainda que essas associações apresentem, entre si e no curso da história, diferenciados graus de coesão e homogeneidade.

\section{RESUMOS}

Com as mudanças ocorridas a partir da década de 1970 no modelo de acumulação capitalista e nos sistemas de proteção social, surgem proposições de políticas sociais portadoras de relevantes referências para a compreensão do presente e das possibilidades de futuro. As políticas de transferência de renda orientadas para cobrir as lacunas de inserção econômico-social são um exemplo importante dessas proposições, e um marco relevante, neste caso, é a criação da Basic Income European Network (BIEN), nos anos 1980, posteriormente redefinida como rede mundial. Neste artigo, a partir da discussão da proposta de Renda Básica da BIEN, com ênfase nos princípios de universalidade e incondicionalidade, apresentamos e discutimos aspectos das políticas de transferência condicionada de renda disseminadas no mesmo contexto, com foco na América Latina, correlacionando suas características formais com o ideário apresentado pela proposta da BIEN e discutindo os impasses, limitações, potencialidades e desafios evidenciados a partir dessa correlação.

Con las transformaciones ocurridas a partir de la década de 1970 en el modelo de acumulación capitalista y en los sistemas de protección social, surgen propuestas de políticas sociales que son referentes para la comprensión del presente y de las posibilidades del futuro. Las políticas de 
transferencia de rentas orientadas a llenar los vacíos de la inserción económica y social, son un ejemplo importante de este tipo de propuestas, para este caso se toma la creación en la década de 1980 del Basic Income European Network (BIEN) (Red de Ingreso Básico Europeo). En este artículo se discute la propuesta de renta básica contenida en la - BIEN - bajo la óptica de los principios de universalidad e incondicionalidad. Igualmente se presenta una discusión de los aspectos de la transferencia de renta condicionada enfocadas en América Latina, correlacionando sus características formales con el ideario presentado por la política de BIEN y discutiendo las dificultades, limitaciones, potencialidades y desafíos evidenciados a partir de esta correlación.

Les changements dans le modele d'accumulation capitaliste et dans les systèmes d'assurance social proposent une série de politiques sociales dont l'analyse nous permet d'éclaircir le présent et l'avenir. Dans ce contexte, il faut greffer les transferts sur le revenu, notamment en ce qui concerne à la création du Basic Income European Network (BIEN) dans les années 1980. A partir de la proposition de l'allocation universelle inscrite dans le BIEN, on analyse les politiques de transferts conditionnée sur le revenu en focalisant les défis, limitations et potentialités par rapport à l'Amérique Latine.

Changes in the capitalist model of accumulation and social protection systems from the 1970s resulted in the emergence of propositions of social policies that carried relevant references for understanding the present time and the future possibilities. Income policies directed to covering economic and social integration gaps are an important example of these propositions, and an important landmark is the creation of the Basic Income European Network (BIEN) in the 1980s, later redefined as a global network. From the discussion of the basic income proposal in BIEN, emphasizing the principles of universality and unconditional nature, we present and discuss aspects of conditioned income transfer policies spread in the same context, focusing on Latin America, correlating their characteristics to ideas presented in BIEN's proposal and discussing impasses, limitations, potential and challenges highlighted by this correlation.

\section{ÍNDICE}

Mots-clés: politiques de transferts conditionnée sur le revenu, politique sociale, allocation universelle, Basic Income European Network (BIEN), Amérique Latine.

Palabras claves: Políticas de renta condicionadas, política social, renta básica, Red de Ingreso Básico.

Keywords: Conditional income transfer policies, social policy, basic income, Basic Income Earth Network.

Palavras-chave: Políticas de transferência condicionada de renda, política social, renda básica, Basic Income Earth Network

\section{AUTORES}

\section{EVELINE ALGEBAILE}

Universidade do Estado do Rio de Janeiro

ealgebaile@gmail.com

\section{DENISE RISSATO}

Universidade Estadual do Oeste do Paraná

denise.rissato@hotmail.com 


\section{ROBERTO ARRUDA}

Universidade do Estado do Mato Grosso

roberto_a_arruda@hotmail.com 